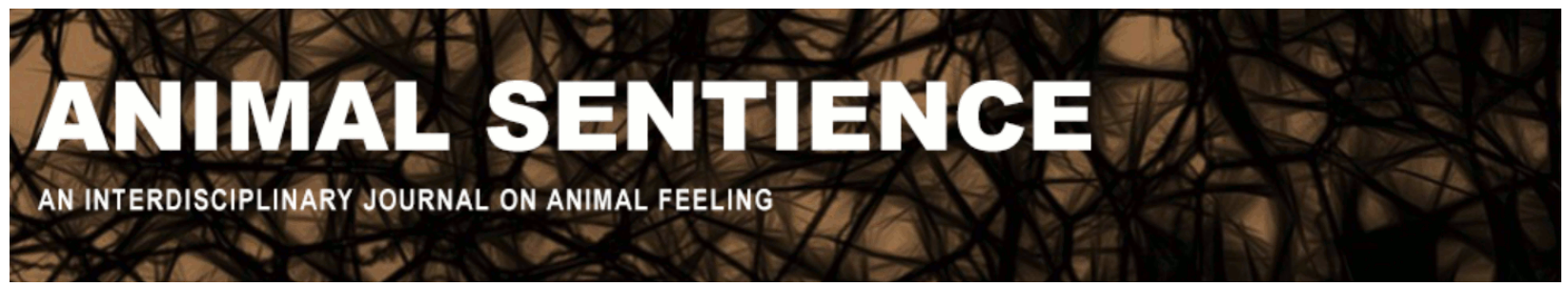

Chiandetti, Cinzia (2018) Chickens play to the crowd. Animal Sentience 17(13) DOI: $10.51291 / 2377-7478.1296$

Date of submission: 2018-01-13

Date of acceptance: 2018-01-25

(c) (i)




\title{
Chickens play to the crowd
}

Commentary on Marino on Thinking Chickens

\author{
Cinzia Chiandetti \\ Department of Life Sciences \\ University of Trieste
}

\begin{abstract}
The time was ripe for Marino's review of chickens' cognitive capacities. The research community, apart from expressing gratitude for Marino's work, should now use it to increase public awareness of chickens' abilities. People's views on many animals are ill-informed. Scientists need to communicate and engage with the public about the relevance and societal implications of their findings.
\end{abstract}

\begin{abstract}
Cinzia Chiandetti, assistant professor in Cognitive Neuroscience and Animal Cognition at the University of Trieste, Italy, and Head of the Laboratory of Animal Cognition, investigates the biological roots of musical preferences, the development of cerebral lateralization and habituation. Awarded the L'Oréal prize for Women in Science, she is active in disseminating the scientific achievements of the field to the broad public. sites.google.com/site/laboratoryanimalcognition/
\end{abstract}

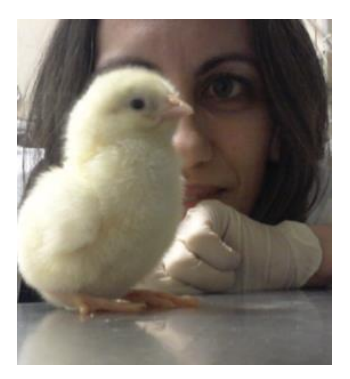

I remember reading the story of Keller and Marian Breland, who, under Skinner's supervision, studied the operant principles for training rats and pigeons, applying them to many other species in the fields of advertising and entertainment. They shaped hamsters, pigs, raccoons - but also chickens - to display very complex behaviors (Breland and Breland, 1951). Their work was acknowledged with great media attention (Bailey and Gillaspy, 2005) and attracted many tourists visiting their "IQ zoo," where they featured intelligent animals displaying (apparent) human-like behaviours. Videos of those times are available on the web ${ }^{1}$, showing chickens dancing on a rotating platform simulating a discotheque with a jukebox on the rear side, or assistant chickens helping children retrieve a ball from an animal-automatic dispenser.

It is in this same context that Breland and Breland (1961) discovered the phenomenon termed "instinctive drift" and published the insightful piece "The misbehaviour of organisms," echoing Skinner's (1938) seminal work "The behavior of organisms." After successful conditioning of a specific response, each animal gradually drifted towards instinctual behaviors related to natural and species-specific responses to getting food, even if it delayed or even prevented receiving reinforcement.

I recount this episode because it teaches us at least two things that coincide with the points I would like to make about Marino's review (2017a,b).

\footnotetext{
${ }^{1}$ http://www3.uca.edu/iqzoo/iqzoo.htm
} 
1. Nature enters the lab. From extensive training under artificial conditions, the instinctive drift, along with other phenomena (e.g., blocking, overshadowing, etc.), subverted the radical behaviourism, demonstrating that biology and ecology are at the basis of learning and cognition. In the laboratory, stimuli and experiences can readily be controlled and operationalized. We are still learning a lot about human and non-human cognition in such "aseptic" experimental conditions today. Consider the case of habituation, often used as a textbook example of nonassociative learning. Results of rigorous tests conducted in the laboratory show that, at least in some circumstances, habituation is instead an associative phenomenon, as first posited by Wagner (1978). Supporting evidence has since been collected for certain responses in the nematode (Rankin, 2000), the crab (Tomsic et al., 1998), the rat (Evans and Hammond, 2000), and the finch (Kruse et al., 2004).

As has happened in other domains (e.g., neurogenesis: Altman, 1962; cortical plasticity: e.g., Jenkins et al., 1990; propensity to engage with the conditioned stimulus vs. the reward: Boakes, 1977), findings with non-human animal models have sometimes preceded those on human beings for the associative interpretation of habituation (Turatto et al., 2017). (See Siddle, 1991, for evidence of associative habituation in omission effects.) Recently, we have shown that habituation also changes in a context-dependent way in chicks (Chiandetti and Turatto, 2017). This means that, starting from early stages of development, chicks can use complex contextual information to adapt their behaviour. Such findings confirm Marino's review of chicks' articulated set of precocial abilities (see also the commentaries of Vallortigara, 2017, and Rogers, 2017) and show the need for more laboratory testing and discussion. Indeed, a recent encyclopedic entry on habituation completely omits this body of literature (Reider, 2017).

I agree with Marino that animals should be observed in their own environment, but controlled experiments are needed too. The ecology of the species can be turned into a variable in the experimental paradigm. A long tradition of studies has taken advantage of chicks' filial attachment to investigate their cognitive abilities (Chiandetti, 2018; Vallortigara and Chiandetti, 2017). We have used this method to show that chicks prefer the acoustic consonance over dissonance (Chiandetti and Vallortigara, 2011), using piano melodies that human infants liked. Whether the preference for consonance is a cultural product or an innate ability is still debated. The finding has been replicated under more naturalistic laboratory conditions. Brooding hens keep clucking while walking around to stimulate chicks' following behavior. With an imprinting object that moved and called the chick by emitting species-specific consonant or dissonant clucking, chicks made the running-wheel spin significantly more with consonance (Baiocchi and Chiandetti, 2016). Such studies have the rigor of behavioural analysis and the ecological breadth of ethology.

2. Engaging and data-driven dissemination. In behaviourists' time, the vast majority of scientists would probably have applauded the Brelands' IQ zoo. What message did it convey to visitors? That animals are little robots or can be "good boys/girls" in remembering human instructions? A rapid survey web search will show that these days, private owners upload videos of their hens trained to play the piano ${ }^{2}$, or exercise chickens to be competitive in agility programs ${ }^{3}$ (not even

${ }^{2}$ https://www.youtube.com/watch?v=U07MP1XbzkE

${ }^{3}$ https://www.youtube.com/watch?v=BlwcG3plAnc 
with shaping but with luring; Kaplan et al., 2002; Chiandetti, 2018). Viewing these web pages, I have the (sad) impression that there has been little improvement since the sixties: training chickens to perform a complex chain of responses for food reward does not give the credit to their high mental ability and complex social life as reported in Marino's review. It also goes along with the new VIP trend to keep ornamental chickens as pets ${ }^{4}$ - with animals exposed to stressful situations from flash photos and dressing accessories.

How much of Marino's synthesis is known to the broad public? People still have many misconceptions and naïve beliefs about the animal kingdom. Questionable experiences are still being provided to the public, such as touch tanks in aquaria. In these settings, people (particularly children) are sent the wrong message, that touching marine life is good, and pleasant for the animal. Another example is Dolphin-Assisted Therapies: despite being denounced long ago as scientifically unsupported (Marino and Lilienfeld, 1998), there are still several active centers (Candelieri, 2017; Candelieri et al., 2015). Other situations are subtler: there is no theoretical reason to prefer a clicker to other effective acoustic signals to shape dogs' (and other animals') behaviour, just convenience (Chiandetti et al., 2016).

Specific interventions are needed, especially in primary and secondary schools (e.g., Sperduti et al., 2012), to make the adults of tomorrow more aware of how to approach animals. In the Internet era, effective dissemination is within reach. We have new technologies such as augmented reality (e.g., Dima et al., 2014; Huges et al., 2004) to convey a message that is informative and engaging. Only by disseminating the findings of our scientific studies can we shape an informed attitude in future generations.

\section{References}

Altman, J (1962) Are new neurons formed in the brains of adult mammals? Science 135: 11271128

Bailey, RE, \& Gillaspy, JA, Jr. (2005) Operant psychology goes to the fair: Marian and Keller Breland in the popular press, 1947-1966. The Behavior Analyst 28(2): 143-159

Baiocchi, V, \& Chiandetti, C (2016) Chicks run harder toward a consonant over a dissonant clucking hen: Biological roots for the appreciation of consonant sounds. Trieste Symposium on Perception and Cognition, Trieste, Italy, November 4, P03

Boakes, RA (1977) Performance on learning to associate a stimulus with positive reinforcement. In Davis, H, \& Hurwitz, HMB (Eds.), Operant-Pavlovian interactions (pp. 67-97). Hillsdale, NJ: Lawrence Erlbaum Associates

Breland, K, \& Breland, M (1951) A field of applied animal psychology. American Psychologist 6: 202-204

Breland, K, \& Breland, M (1961) The misbehaviour of organisms. American Psychologist 16: 681684

Candelieri, I (2017) La cura nell'acqua. Una lettura critica della delfinoterapia. Mimesis, Milano

\footnotetext{
${ }^{4}$ https://www.yahoo.com/entertainment/blogs/celeb-news/tiffani-thiessen-other-celebrities-with-chickens190513882.html
} 
Candelieri, I, Chiandetti, C, \& Cattaruzza, S (2015) Healing dolphins? Cognitive and perceptual criticisms in dolphin-assisted therapy. Trieste Symposium on Perception and Cognition, Trieste, Italy, November 13, P05

Chiandetti, C (2018) Hier bin ich: Wo bist du? The affiliative imprinting phenomenon in the modern study of animal cognition. Gestalt Theory, in press

Chiandetti, C (2018) Shaping. In Vonk, J, \& Shackelford, TK (Eds.), Encyclopedia of animal cognition and behavior. Springer, New York

Chiandetti, C, \& Turatto, M (2017) Context-specific habituation of the freezing response in newborn chicks. Behavioral Neuroscience 131(5): 437-446

Chiandetti, C, \& Vallortigara, G (2011) Chicks like consonant music. Psychological Science 22: 1270-1273

Chiandetti, C, Avella, S, Fongaro, E, \& Cerri, F (2016) Can clicker training facilitate conditioning in dogs? Applied Animal Behaviour Science 184: 109-116

Dima, M, Hurcombe, L, \& Wright, M (2014) Touching the past: Haptic augmented reality for museum artefacts. In Shumaker, R., \& Lackey, S (Eds.), Virtual, augmented and mixed reality: Applications of virtual and augmented reality (VAMR 2014: Lecture Notes in Computer Science, vol. 8526). Springer, Cham

Evans, JG, \& Hammond, GR (1983). Differential generalization of habituation across contexts as a function of stimulus significance. Animal Learning \& Behavior 11: 431-434

Hughes, CE, Smith, E, Stapleton, C, \& Hughes, DE (2004) Augmenting museum experiences with mixed reality. Proceedings of Knowledge Sharing and Collaborative Engineering 2004. St. Thomas, US Virgin Islands

Jenkins, WM, Merzenich, MM, Ochs, MT, Allard, T, \& Guíc-Robles, E (1990) Functional reorganization of primary somatosensory cortex in adult owl monkeys after behaviorally controlled tactile stimulation. Journal of Neurophysiology 63(1): 82-104

Kaplan, F, Oudeyer, P-Y, Kubinyi, E, \& Miklósi, Á (2002) Robotic clicker training. Robotics and Autonomous Systems 38: 197-206

Kruse, AA, Stripling, R, \& Clayton, DF (2004) Context-specific habituation of the zenk gene response to song in adult zebra finches. Neurobiology of Learning and Memory 82: 99-108

Marino, L (2017a) The inconvenient truth about thinking chickens. Animal Sentience 17(1)

Marino, L (2017b) Thinking chickens: A literature review of cognition, emotion, and behavior in the domestic chicken. Animal Cognition 20(2): 127-141

Marino, L, \& Lilienfeld, SO (1998) Dolphin-assisted therapy: Flawed data, flawed conclusions. Anthrozoös 11: 194-200

Rankin, $\mathrm{CH}$ (2000) Context conditioning in habituation in the nematode Caenorhabditis elegans. Behavioral Neuroscience 114: 496-505

Reider (2017) Habituation. In Vonk, J, \& Shackelford, TK (Eds.), Encyclopedia of animal cognition and behavior. Springer, New York

Rogers, LJ (2017) Chickens' brains, like ours, are lateralized. Animal Sentience 17(3)

Skinner, BF (1938) The behavior of organisms: An experimental analysis. Oxford, England: Appleton-Century

Sperduti, A, Crivellaro, F, Rossi, PF, \& Bondioli, L (2012) 'Do octopuses have a brain?' Knowledge, perceptions and attitudes towards neuroscience at school. PLOS ONE 7(10): e47943 
Tomsic, D, Pedreira, ME, Romano, A, Hermitte, G, \& Maldonado, H (1998) Context-us association as a determinant of long-term habituation in the crab Chasmagnathus. Animal Learning \& Behavior 26: 196-209

Turatto, M, Bonetti, F, \& Pascucci, D (2017) Filtering visual onsets via habituation: A contextspecific long-term memory of irrelevant stimuli. Psychonomic Bulletin \& Review, advance online publication

Vallortigara, G (2017) Sentience does not require "higher" cognition. Animal Sentience 17(6) Vallortigara, G, \& Chiandetti, C (2017) Objects and space in an avian brain. In ten Cate, C, \& Healy, SD (Eds.), Avian cognition (pp. 141-162). Cambridge University Press

Wagner, A (1978) Expectancies and the priming of STM. In Hulse, SH, Fowler, H, \& Honig, R (Eds.), Cognitive processes in animal behaviour (pp. 177-209). Hillsdale, NJ: Erlbaum 